\title{
Lead-Free Solders: Focus on Fundamentals, Reliability, and Applications
}

\author{
BABAK ARFAEI $I^{1,2,3}$ \\ 1.-APL Laboratory, Universal Instruments, Conklin, NY 13748, USA. 2.-Physics Department, \\ Binghamton University, Binghamton, NY 13902, USA. 3.—e-mail: babak.arfaei@binghamton.edu
}

\begin{abstract}
Although lead-free solders have been adopted by much of the commercial electronics industry, the implementation of lead-free processes still faces some challenges. The performance of lead-free solder joints in high-reliability aerospace, military, and medical applications is still a concern. There is a clear shortcoming in the ability to predict the lifetime of lead-free assemblies in service. Thus, a common objective of current researchers is to develop a fundamental understanding of the initial solder microstructure, its evolution under various reliability test conditions, and the failure mechanism of lead-free solder joints. Their research focus often includes control of the solidification microstructure by understanding the nucleation of Sn, investigating the role of precipitates and intermetallic compounds at the interface during the deformation of solders, and examining the effect of $\mathrm{Sn}$ grain morphology and orientation on the thermomechanical response of solder joints. ${ }^{1-3}$ Researchers are trying to better understand strain-enhanced coarsening, recrystallization, and crack initiation and propagation to develop models that can explain the failure mechanism in different reliability experiments. ${ }^{2,3}$ One goal of this research is to provide a microstructurally adaptive model that can accurately predict the life of soldered electronic devices.
\end{abstract}

Concurrent with the transition to lead-free manufacturing, the electronics industry is experiencing a major revolution associated with the introduction of $2.5 \mathrm{D}$ and $3 \mathrm{D}$ packaging technologies. ${ }^{4-6}$ There, the lead-free challenges faced by materials scientists become even more complex as the size of electronic packages and solder interconnects shrink to enable deployment of thinner, faster devices. New

Babak Arfaei is the guest editor for the Electronic Packaging \& Interconnection Materials Committee of the TMS Functional Materials Division, and coordinator of the topic Progress with Lead-Free Solders in this issue. challenges will be introduced as the entire solder joint may be transformed into intermetallic compounds during assembly or operation. Reducing the size of the solder bumps additionally results in higher current density and increased power dissipation, making electromigration reliability more of a concern. More efficient thermal interface materials are needed to increase the heat flux from die to thermal solution. ${ }^{5,6}$ Moreover, the electronic industry is seeking new solder alloys that are low cost but have acceptable reliability performance in both high-strain applications such as drop/shock and vibration and low-strain applications such as thermal and power cycling. The addition of various fourth and fifth alloying elements to $\mathrm{SnAgCu}$ solder alloys is being investigated. The effects of these additional elements on mechanical properties, failure mechanisms, and other reliability phenomena such as Sn whisker formation are not fully understood. In addition, there is a desire among the industrial electronics community to develop new solder alloys for high-temperature applications such as aviation engine controls and downhole drilling electronics as these industries anticipate a future transition to lead-free electronic assembly. ${ }^{3}$

Several of these topics were discussed during the $\mathrm{Pb}$-Free Solders and Emerging Interconnect and Packaging Materials Symposium at the TMS 2014 Annual Meeting in San Diego, California. Researchers from industry and academia from different parts of the globe shared their latest research findings in this leading symposium on electronic packaging. More than 60 works were presented in 8 different sessions. A poster session was also organized to include the numerous additional contributions. Three of those technical presentations are presented in this issue of $J O M$, while others will be published in a special issue of the Journal of Electronic Materials as well as other journals published by TMS.

The first article, by E. J. Cotts et al., discusses the effect of impurities on the solidification behavior 
and microstructure of lead-free solder bumps. The authors carefully measured the nucleation rate and solidification temperature of various $\mathrm{Sn}-\mathrm{M} x$ alloys (where $\mathrm{M}$ was $\mathrm{Co}, \mathrm{Ni}, \mathrm{Ag}$, or $\mathrm{Cu}$ and $x$ was the concentration of impurity atoms). Their results showed that the intermetallic compounds found in near-eutectic $\mathrm{SnAgCu}\left(\mathrm{Ag}_{3} \mathrm{Sn}\right.$ and $\left.\mathrm{Cu}_{6} \mathrm{Sn}_{5}\right)$ were both ineffective in promoting solidification of $\mathrm{Sn}$ in freestanding samples. Such fundamental studies on the nucleation and solidification behavior of leadfree solder joints are anticipated to be critical in developing new low-cost alloys that meet reliability requirements for both mechanical (drop/shock, vibration) and thermal (thermal cycling) performance of lead-free solder joints, particularly for smaller microbumps.

The second article, by S. Meschter et al., summarizes the results of a large experiment performed to evaluate the formation of Sn whiskers in various SAC 305 assemblies with and without rare earth elements (REEs). Various test conditions (power cycling, thermal cycling, and high temperature/high humidity) were evaluated, and Sn whiskers were measured and assessed in each test condition. The results revealed that assembly contamination, the presence of REE, the properties of the substrate material, the thickness of the solder, and the test conditions can all significantly affect the formation and growth of Sn whiskers. Such detailed studies on the formation of $\mathrm{Sn}$ whiskers are essential to establish reliability risk levels in high-reliability aerospace and military applications.

The third article, by F. Y. Ouyang et al., reports on the electromigration resistance of $\mathrm{Sn} / \mathrm{Cu}$ columns and compares the results with that of pure Sn. A new test sample geometry was defined and used to identify electromigration effects in solder joints. The Sn layer was replaced with alternating $\mathrm{Sn}$ and $\mathrm{Cu}$ columns, as opposed to layers, with different repeat distances. The results showed that by using this new structure, both the rate of void nucleation and coalescence induced by electromigration were delayed due to a lower current density in the current crowd- ing region leading to the higher electromigration resistance of $\mathrm{Cu}$. Such studies could help to design structures with better electromigration resistance and alleviate one of the major concerns as the package and bump size decrease.

We look forward to another exciting TMS meeting in March 2015 at Orlando, Florida. We would like to invite all materials scientists interested in electronic packaging to attend the Pb-Free Solders and Emerging Interconnect and Packaging Materials Symposium and Committee Meeting.

The following papers being published under the topic of Progress with Lead-Free Solders provide excellent details and research on the subject. To download any of the papers, follow the url http:// link.springer.com/journal/11837/66/11/page/1 to the table of contents page for the November 2014 issue (vol. 66, no. 11).

- "The Nucleation of Sn in Undercooled Melts: The Effect of Metal Impurities" Gregory Parks, Austin Faucett, Craix Fox, Jake Smith, and Eric Cotts.

- "Whisker Formation on SAC305 Soldered Assemblies" by S. Meschter, P. Snugovsky, Z. Bagheri, E. Kosiba, M. Romansky, J. Kennedy, L. Snugovsky, and D. Perovic.

- "Enhanced Electromigration Resistance of $\mathrm{Pb}$ Free Solders by Using Cu/Sn Composite Structure" Shih-Hsun Lin and Fan-Yi Ouyang.

\section{REFERENCES}

1. Special Issue on Lead-Free Solders and Processing Issues in Microelectronic Packaging, J. Electron. Mater., 1 (2014), $1-298$.

2. Proceedings of 64th Electronic Components and Technology Conference (ECTC) (IEEE, Piscataway, NJ, 2014).

3. Proceedings of SMTA Int. Conf. (Surface Mount Technology Association, Edina, MN, 2013).

4. iNEMI 2013 Roadmap (International Electronics Manufacturing Initiative, Herndon, VA, 2013).

5. J. Lau, Through-Silicon Vias (TSVS) for $3 D$ Integration (Columbus, OH: McGraw-Hill, 2012).

6. Presentations from the IEEC-CPMT Symposium on Electronics Packaging and 2.5D/3D, Binghamton University, Binghamton, NY, 15-16 October 2013. 